\title{
Synthesis and Molecular Weight Dependent Optical Properties of Mono-Alkoxy Substituted Polythiophenes
}

\author{
Zhong-Biao ZHANG and Michiya FUJIKI ${ }^{\dagger}$ \\ NTT Basic Research Laboratories and CREST-JST, \\ 3-1 Wakamiya, Morinosato, Atsugi, Kanagawa 243-0198, Japan
}

(Received February 28, 2001; Accepted May 11, 2001)

\begin{abstract}
Poly(3-alkoxythiophene)s with moderately high molecular weights, which exhibit good solubility and film-forming ability, were successfully synthesized by the nickel (0) coupling reaction in good yields. The introduction of a branched side chain resulted in a molecular weight higher than that of the straight one. Broad photoluminescence (PL), ranging from 579 to $684 \mathrm{~nm}$, was readily obtained by choosing the appropriate molecular weight sample of a mother polymer. This may provide a new method for evaluating organic luminescent materials.
\end{abstract}

KEY WORDS Poly(3-alkoxythiophene) / Nickel Catalyst / Molecular Weight / Optical Properties /

$\pi$-Conjugating polythiophenes have been considered promising candidates for polymer light-emitting diodes (LEDs), due to the tunability of emission colors, processability, and thermal and chemical stabilities. ${ }^{1}$ Emission color closely depends on the extent of the effective conjugation along the backbone, which is mainly controlled by tailoring the structures of the main chain and side chain. ${ }^{2,3}$ Poly(alkoxythiophene)s are known to be useful as hole injection layers to improve the charge transport ability of LEDs, due to higher charge carrier mobility, lower oxidation potential, and better stability in the oxidized state, compared to alkyl substituted polythiophenes. ${ }^{4}$ Although the synthesis of alkyl and di-alkoxy substituted polythiophenes has been well established, ${ }^{5,6}$ the synthesis of monoalkoxy substituted polythiophenes still remains a problem due to the low molecular weight and poor solubility. ${ }^{7-14}$ This paper reports the synthesis and optical properties of three poly(3-alkoxythiophene) derivatives with moderately high molecular weights, which exhibit good solubility and film-forming ability. The introduction of a branched side chain in the monomer increased molecular weight of the polymer. These results may lead to a facile and inexpensive method for providing variable emission color by choosing the appropriate molecular weight samples of a single mother polymer.

\section{EXPERIMENTAL}

\section{Measurements}

Molecular weights were evaluated by size exclusion chromatography (SEC) on a Shodex KF806 M column (eluent THF, $30^{\circ} \mathrm{C}$ ) in a Shimadzu liquid chromatography instrument equipped with a photodiode array detector based on the calibration using polystyrene stan- dards. Ultraviolet-visible (UV-vis) spectra (room temperature; $21^{\circ} \mathrm{C}$ ) were recorded on a JASCO V-570 spectrometer. Fluorescence spectra (room temperature; $21^{\circ} \mathrm{C}$ ) were recorded on a Hitachi F-850 spectrophotometer. NMR spectra were recorded on a Varian Unity 300 spectrometer relative to the TMS internal standard in chloroform- $d$.

\section{Materials}

3-Methoxythiophene was purchased from Aldrich Chemical Co. $(R)-(-)-2-O c t a n o l ~(\geq 99 \%$ e.e. (enantiomeric excess)) was purchased from AZmax Co., Japan. They were used without further purification.

\section{Monomer Synthesis}

3-Alkoxy substituted thiophenes were prepared by transetherification reaction between 3methoxythiophene and corresponding primary and secondary alcohols in the presence of a catalytic amount of sodium hydrogen sulfate in toluene according to the literature, ${ }^{15}$ then purified by vacuum distillation. 3-Alkoxy-2,5-dibromothiophenes were prepared by bromination of the 3-alkoxythiophenes with 2.2 equiv. of $N$-bromosuccinimide (NBS) in dichloromethane at room temperature, ${ }^{16}$ and purified by column chromatography with hexane as the eluent.

\section{3-n-Octoxythiophene}

Yield $88.6 \%$, bp $80-82^{\circ} \mathrm{C} / 0.25 \mathrm{mmHg}$. ${ }^{1} \mathrm{H}$ NMR $\left(\mathrm{CDCl}_{3}\right): 0.88(\mathrm{t}, J=6.8 \mathrm{~Hz}, 3 \mathrm{H}), 1.29-1.44(\mathrm{~m}, 10 \mathrm{H})$, $1.76(\mathrm{p}, J=6.6 \mathrm{~Hz}, J=7.6 \mathrm{~Hz}, 2 \mathrm{H}), 3.93(\mathrm{t}, J=$ $6.6 \mathrm{~Hz}, 2 \mathrm{H}), 6.21-6.23(\mathrm{~m}, 1 \mathrm{H}), 6.73-6.76(\mathrm{~m}, 1 \mathrm{H})$, and 7.15-7.18 (m, 1H) ppm. ${ }^{13} \mathrm{C} \mathrm{NMR}\left(\mathrm{CDCl}_{3}\right): 14.10$, 22.66, 26.06, 29.23, 29.27, 29.35, 31.81, 72.30, 96.95, $119.55,124.50$, and $158.06 \mathrm{ppm}$.

${ }^{\dagger}$ To whom correspondence should be addressed. 


\section{3-(2-Octoxy)thiophene}

Yield $64.0 \%$, bp $70-71{ }^{\circ} \mathrm{C} / 0.25 \mathrm{mmHg}$. ${ }^{1} \mathrm{H}$ NMR $\left(\mathrm{CDCl}_{3}\right): 0.88(\mathrm{t}, J=6.8 \mathrm{~Hz}, 3 \mathrm{H}), 1.28-1.74(\mathrm{~m}, 13 \mathrm{H})$, 4.19 (sextet, $J=6.1 \mathrm{~Hz}, 1 \mathrm{H}), 6.21-6.23(\mathrm{~m}, 1 \mathrm{H}), 6.71-$ $6.74(\mathrm{~m}, 1 \mathrm{H})$, and $7.13-7.16(\mathrm{~m}, 1 \mathrm{H}) \mathrm{ppm} .{ }^{13} \mathrm{C} \mathrm{NMR}$ $\left(\mathrm{CDCl}_{3}\right): 14.08,19.64,22.60,25.54,29.29,31.41$, $36.41,76.52,98.32,120.27,124.27$, and $156.85 \mathrm{ppm}$.

\section{3-((R)-2-Octoxy)thiophene}

Yield $63.0 \%$, bp $70-72^{\circ} \mathrm{C} / 0.30 \mathrm{mmHg}, \alpha_{\mathrm{D}}^{25}=$ $-2.26^{\circ}$ (neat). ${ }^{1} \mathrm{H} \mathrm{NMR}\left(\mathrm{CDCl}_{3}\right): 0.88(\mathrm{t}, J=6.8 \mathrm{~Hz}$, $3 \mathrm{H}), 1.28-1.77(\mathrm{~m}, 13 \mathrm{H}), 4.19$ (sextet, $J=6.1 \mathrm{~Hz}$, $1 \mathrm{H}), 6.20-6.22(\mathrm{~m}, 1 \mathrm{H}), 6.70-6.74(\mathrm{~m}, 1 \mathrm{H})$, and 7.13$7.15(\mathrm{~m}, 1 \mathrm{H}) \mathrm{ppm} .{ }^{13} \mathrm{C} \mathrm{NMR}\left(\mathrm{CDCl}_{3}\right): 14.08,19.64$, $22.62,25.55,29.30,31.83,36.43,76.52,98.33,120.28$, 124.27 , and $156.87 \mathrm{ppm}$.

\section{2,5-Dibromo-3-n-octoxythiophene}

Yield 56.8\%. ${ }^{1} \mathrm{H}$ NMR $\left(\mathrm{CDCl}_{3}\right): 0.88(\mathrm{t}, J=6.8 \mathrm{~Hz}$, $3 \mathrm{H}), 1.28-1.43(\mathrm{~m}, 10 \mathrm{H}), 1.73(\mathrm{p}, J=6.6 \mathrm{~Hz}, J=$ $7.6 \mathrm{~Hz}, 2 \mathrm{H}), 4.19(\mathrm{t}, J=6.6 \mathrm{~Hz}, 2 \mathrm{H})$, and $6.76(\mathrm{~s}, 1 \mathrm{H})$ ppm. ${ }^{13} \mathrm{C}$ NMR $\left(\mathrm{CDCl}_{3}\right): 14.10,22.65,26.07,29.23$, $29.28,29.34,31.92,75.31,91.15,121.43,122.50$, and $154.36 \mathrm{ppm}$.

\section{2,5-Dibromo-3-(2-octoxy)thiophene}

Yield $84.0 \% .{ }^{1} \mathrm{H} \mathrm{NMR}\left(\mathrm{CDCl}_{3}\right): 0.88(\mathrm{t}, J=6.8 \mathrm{~Hz}$, $3 \mathrm{H}), 1.26-1.77(\mathrm{~m}, 13 \mathrm{H}), 4.14$ (sextet, $J=6.1 \mathrm{~Hz}$, $1 \mathrm{H})$, and $6.72(\mathrm{~s}, 1 \mathrm{H}) \mathrm{ppm} .{ }^{13} \mathrm{C} \mathrm{NMR}\left(\mathrm{CDCl}_{3}\right): 14.08$, 20.13, 22.59, 25.34, 29.25, 31.77, 36.50, 79.50, 92.59, 109.54, 122.30, and $153.19 \mathrm{ppm}$.

\section{2,5-Dibromo-3-((R)-2-octoxy)thiophene}

Yield 70.0\%. ${ }^{1} \mathrm{H}$ NMR $\left(\mathrm{CDCl}_{3}\right): 0.88(\mathrm{t}, J=6.8 \mathrm{~Hz}$, $3 \mathrm{H}), 1.26-1.78(\mathrm{~m}, 13 \mathrm{H}), 4.14$ (sextet, $J=6.1 \mathrm{~Hz}$, $1 \mathrm{H})$, and $6.72(\mathrm{~s}, 1 \mathrm{H}) \mathrm{ppm} .{ }^{13} \mathrm{C} \mathrm{NMR}\left(\mathrm{CDCl}_{3}\right): 14.08$, $20.13,22.59,25.34,29.23,31.77,36.50,79.5,92.61$, $109.56,122.32$, and $153.19 \mathrm{ppm}$.

\section{Polymer Synthesis}

The zero-valent nickel coupling reaction developed by Yamamoto et al. ${ }^{17}$ was used for polymerization. To a mixture of $0.85 \mathrm{~g}$ (5.4 mmol) 1,1'-bipyridyls, $1.50 \mathrm{~g}$ (5.4 mmol), bis(cyclooctadiene) $\mathrm{Ni}(0)\left(\mathrm{Ni}(\mathrm{COD})_{2}\right)$, $0.48 \mathrm{~g}(4.5 \mathrm{mmol})$ cyclooctadiene (COD), and $15 \mathrm{~mL}$ $N, N$-dimethylformamide (DMF), $1.68 \mathrm{~g}$ (4.5 mmol) 3alkoxy-2,5-dibromothiophene in $18 \mathrm{~mL}$ DMF added slowly under an argon atmosphere. After stirring at $60^{\circ} \mathrm{C}$ for $18 \mathrm{~h}, 200 \mathrm{~mL}$ acidic methanol (containing $10 \% 1 \mathrm{~N}$ hydrochloric acid in volume) added. The formed solid was collected by filtration, and successively washed with acidic methanol, hot ethylenediaminetetraacetic acid (EDTA) aqueous solution $(\mathrm{pH}$
3.8), hot EDTA aqueous solution ( $\mathrm{pH}$ 9.0), and water, and then dried under vacuum at room temperature overnight. The crude product was purified by precipitation from a mixture of chloroform and methanol to give a blue-violet solid.

\section{Poly(3-n-Octoxythiophene) (P1)}

Yield $71.4 \% .{ }^{13} \mathrm{C}$ NMR $\left(\mathrm{CDCl}_{3}\right): 14.12,22.70$, 26.10, 29.37, 29.64, 30.31, 31.91, 71.92, 111.77 (2C), $131.86,153.25 \mathrm{ppm}$.

\section{Poly[3-(2-Octoxy)thiophene] (P2)}

Yield 75.6\%. ${ }^{13} \mathrm{C}$ NMR $\left(\mathrm{CDCl}_{3}\right): 14.07,20.18$, $22.62,25.59,29.35,31.78,36.74,78.40,114.05$ (2C), $133.27,150.91 \mathrm{ppm}$.

\section{Poly\{[3-(R)-2-Octoxy]thiophene $\}$ (P3)}

Yield $77.9 \%$. ${ }^{13} \mathrm{C}$ NMR $\left(\mathrm{CDCl}_{3}\right): 14.07,20.20$, $22.62,25.59,29.35,31.80,36.74,78.34,112.53$ (2C), $132.54,151.41 \mathrm{ppm}$.

\section{Fractionation of Polymers}

Fractionated polythiophenes were successively obtained by Soxhlet extraction using ethanol (fraction 1), $n$-hexane (fraction 2), and tetrahydrofuran (THF) (fraction 3), each for $24 \mathrm{~h}$. Different molecular weight samples were obtained after evaporation of the solvent.

\section{RESULTS AND DISCUSSION}

\section{Synthesis of Polymer}

The synthetic route is shown in Scheme 1. The unfractionated polymers have moderately high molecular weights $\left(M_{\mathrm{w}}\right)$ (Table I) ranging from 5000-10000 (To our knowledge, this may be the highest $M_{\mathrm{w}}$ of monoalkoxy substituted polythiophenes prepared chemically and electrochemically), and are readily soluble in THF, toluene, and chloroform. The thin solid films can be easily prepared by either solvent-casting or spin-

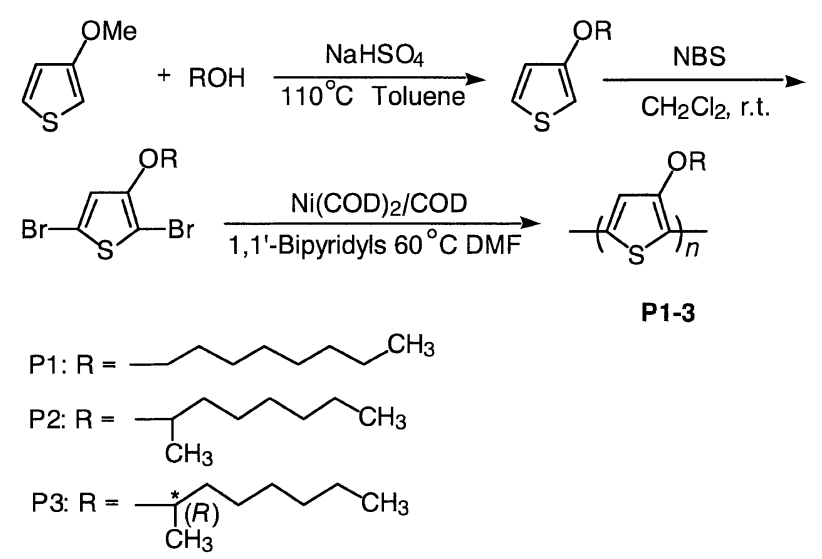

Scheme 1. Synthesis of poly(3-alkoxythio-phene)s P1-P3. 
Table I. Fractionation of P1-P3

\begin{tabular}{|c|c|c|c|c|}
\hline \multicolumn{2}{|c|}{ Polymers } & \multirow{2}{*}{$\frac{\frac{\text { Content }}{\%}}{-}$} & \multirow{2}{*}{$\frac{\frac{M_{\mathrm{w}}}{\left(\times 10^{3}\right)}}{4.6}$} & \multirow{2}{*}{$\frac{M_{\mathrm{w}} / M_{\mathrm{n}}}{1.35}$} \\
\hline$\overline{\mathrm{P} 1}$ & Before & & & \\
\hline & Fr.1 & 8.3 & 1.7 & 1.27 \\
\hline & Fr.2 & 23.6 & 2.0 & 1.27 \\
\hline & Fr.3 & 67.9 & 5.6 & 1.35 \\
\hline \multirow[t]{4}{*}{ P2 } & Before & - & 10.2 & 3.01 \\
\hline & Fr.1 & 4.1 & 1.9 & 1.51 \\
\hline & Fr.2 & 17.9 & 3.1 & 1.61 \\
\hline & Fr.3 & 78.3 & 12.4 & 2.78 \\
\hline \multirow[t]{4}{*}{ P3 } & Before & - & 10.3 & 2.89 \\
\hline & Fr.1 & 6.5 & 2.8 & 1.53 \\
\hline & Fr.2 & 20.2 & 5.1 & 1.39 \\
\hline & Fr.3 & 73.0 & 13.8 & 2.77 \\
\hline
\end{tabular}

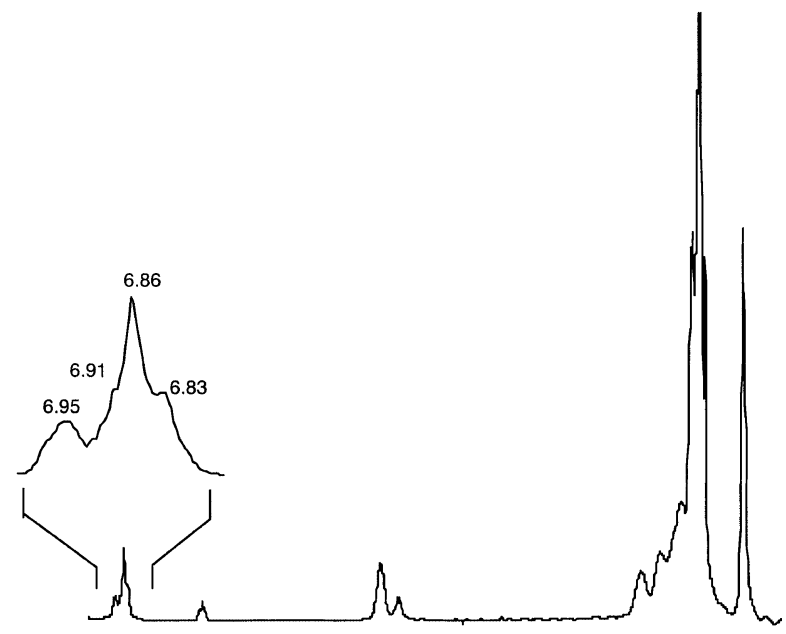

ppm

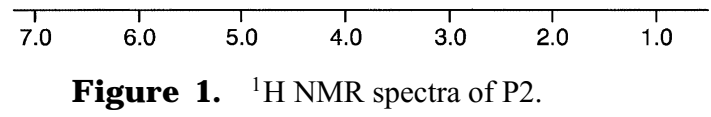

coating techniques. Improvements on $M_{\mathrm{w}}$ and solubility, compared to those of poly(3-methoxythiophene) and poly(3-methoxyethoxythiophene) prepared by Yamamoto et al. ${ }^{12}$ using the same method, may be due to the longer length of the aliphatic side chains in P1-P3.

The regioregularity of the unfracationated $\mathrm{P} 2$ was characterized by ${ }^{1} \mathrm{H}$ NMR using Rieke's method. ${ }^{18}$ There are four peaks in the aromatic region $(\delta 6.83$, $6.86,6.91,6.95 \mathrm{ppm}$ ) for the 4-position hydrogen of the thiophene rings due to the possible triad sequences (HT-HT, TT-HT, HT-HH, and TT-HH) ${ }^{19}$ (Figure 1). Although the exact content of different triads is difficult to calculate, due to the overlapping, it is clear that the intensity of the peaks at 6.86 (TT-HT) and 6.95 (TT-HH) ppm is higher than that of the other two, which indicates that TT coupling is initially dominant (Scheme 2). Our result is almost consistent with the regioselectivity of the TT coupling during the nickel coupling reaction for the preparation of the poly(3-

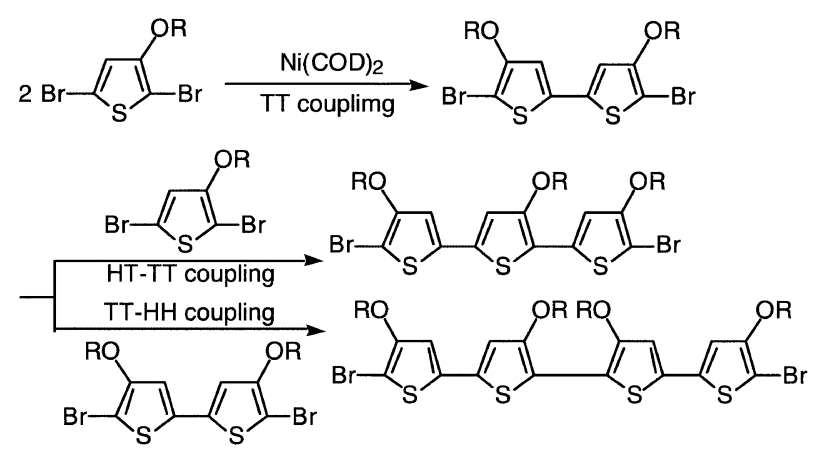

Scheme 2. Regioselectivity of nickel( 0$)$ coupling reaction.

alkylthiophene)s. ${ }^{17}$

In the unfractionated polymers, $M_{\mathrm{w}} \mathrm{S}$ of $\mathrm{P} 2$ and $\mathrm{P} 3$ are twice as high as that of $\mathrm{P} 1$. The origin of this difference may be attributed to the side chains: P1, straight long aliphatic chain, while $\mathrm{P} 2$ and $\mathrm{P} 3,{ }^{20}$ branched chains with a methyl group at the nearest carbon to the thiophene ring. Steric hindrance in the TT-coupled dimer of $\mathrm{P} 2$ and $\mathrm{P} 3$ is therefore expected to be larger than that of P1, which may reduce reactivity for further propagation. It seems that the lower reactivity of the monomer during the initial stage may favor the growth of polymer chains instead of the growth of new chains, and thus favor the production of high molecular weight products. The result that the higher molecular weight poly(3-alkoxythiophene)s can be obtained by using a relatively weak oxidant ${ }^{11}\left(\mathrm{Cu}\left(\mathrm{ClO}_{4}\right)_{2}\right.$ instead of $\left.\mathrm{FeCl}_{3}\right)$ or at lower temperature ${ }^{14}\left(0^{\circ} \mathrm{C}\right.$ instead of $\left.20^{\circ} \mathrm{C}\right)$ may also support this idea. ${ }^{21}$

\section{Molecular Weight-Dependent Photoluminescence (PL) and UV-vis Absorption Characteristics}

Fractionated samples of P1-P3 (Table I) showed significantly $M_{\mathrm{w}}$-dependent optical properties (Table II). The broad PL, ranging from 579 to $684 \mathrm{~nm}$ was readily obtained by choosing an adequate $M_{\mathrm{w}}$ sample of the mother polymer, although quantum yields $(\eta)$ of PL markedly decreased with the increase in $M_{\mathrm{w}}$. UV-vis and PL spectra of P1 in chloroform solution are shown in Figure 2. The first fraction of P1 $\left(M_{\mathrm{w}} 1.7 \times 10^{3}\right) \mathrm{ab}-$ sorbs at $472 \mathrm{~nm}$ and emits a yellow color $\left(\lambda_{\max } 579 \mathrm{~nm}\right)$ with $\eta$ of $c a .1 \%$. The second $\left(M_{\mathrm{w}} 2.0 \times 10^{3}\right)$ absorbs at $552 \mathrm{~nm}$ and emits red $\left(\lambda_{\max } 655 \mathrm{~nm}\right)$ with slightly lower $\eta$ of $c a .0 .26 \%$, and the third $\left(M_{\mathrm{w}} 5.6 \times 10^{3}\right) \mathrm{ab}-$ sorbs at $583 \mathrm{~nm}$ and emits at $676 \mathrm{~nm}$ with the lowest $\eta$ of only $0.043 \%$.

The optical properties of P1-P3 in the aggregated form were measured in a mixed chloroform (good solvent) and acetonitrile (poor solvent) system at the ratio of 1:9 (Table III). Absorption and emission spectra in the aggregated forms have similar molecular weight dependence to that of the molecularly dispersed forms, 
Table II. Optical properties of different fractions of P1-P3 in chloroform at $21^{\circ} \mathrm{C}$

\begin{tabular}{cccl}
\hline Polymer & $\begin{array}{c}\lambda_{\max }(\mathrm{abs}) / \mathrm{nm}, \varepsilon^{\mathrm{b}} / 10^{3}, \\
\text { Stoke Shifts } / 10^{3} \mathrm{~cm}^{-1}\end{array}$ & $\begin{array}{c}\lambda_{\max }^{\mathrm{a}}(\mathrm{PL}) / \mathrm{nm}, \\
\eta / \%\end{array}$ \\
\hline P1 & Fr.1 & $472,1.8,3.92$ & $579,1.05$ \\
& Fr.2 & $552,10.5,2.85$ & $655,0.26$ \\
& Fr.3 & $583,9.6,2.36$ & $676,0.043$ \\
P2 & Fr.1 & $520,7.8,2.97$ & $615,0.47$ \\
& Fr.2 & $575,11.6,2.17$ & $657,0.050$ \\
& Fr.3 & $585,12.3,2.47$ & $684,0.042$ \\
P3 & Fr.1 & $509,7.1,3.62$ & $624,0.86$ \\
& Fr.2 & $569,10.3,2.69$ & $667,0.15$ \\
& Fr.3 & $588,14.2,2.30$ & $680,0.050$ \\
\hline
\end{tabular}

${ }^{a} \lambda_{\max }(\mathrm{PL})$ was recorded at $\lambda_{\max }(\mathrm{abs})$ excitation, whereas the absorbance of each fraction was $c a$. 0.05. Quantum yields $(\eta)$ were calculated in an integrating sphere with quinine sulfate as the standard. ${ }^{\mathrm{b}} \varepsilon$ was normalized by (thiophene repeating unit) ${ }^{1} \mathrm{dm}^{3} \mathrm{~cm}^{-1}$.

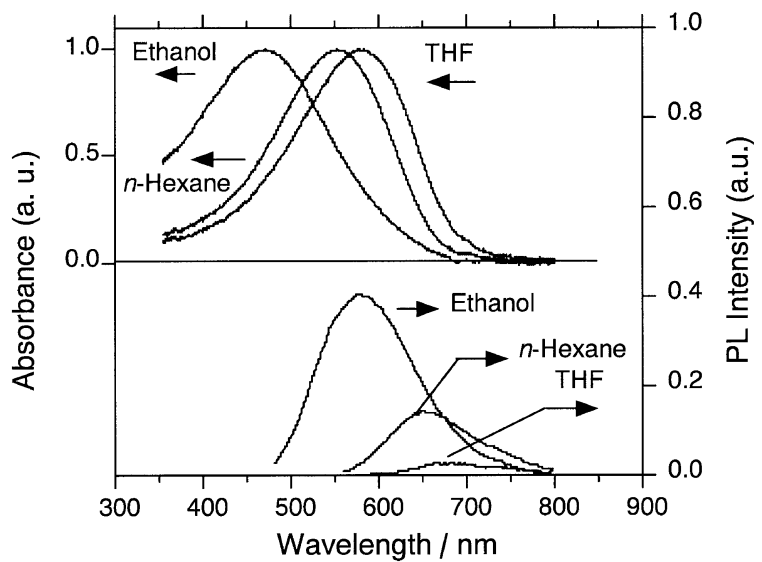

Figure 2. UV-vis and PL spectra of three fractions of P1 in chloroform solution at $21^{\circ} \mathrm{C}$ (PL intensity was normalized to fraction 1).

though the emission efficiency decreased, especially in fractions 2 and 3, which can be explained by the proximity of the polymer main chains in the aggregates. ${ }^{3}$ Very weak emission with same molecular weight dependence was found in the thin solid film state of P2 (Table III). ${ }^{22}$

In the molecularly dispersed and aggregated forms of P1-P3, difference in the absorption $\lambda_{\max }$ between the second and third fractions is much smaller than that between the first and second, indicating that the effective conjugation length tends to saturation as $M_{\mathrm{w}}$ increases. The marked difference in $\eta$ between the first and second fractions of about one order of magnitude may be explained by the fact that as the molecular weight increases, although the conjugation along the polythiophene backbone should increase, leading to red shifts in the absorption and emission, the non-radiative relaxation of the photoexcited energy is effectively enhanced by the localized structure, resulting in the ob-
Table III. Optical properties of different fractions of P1-P3 in aggregation form and solid state at $21^{\circ} \mathrm{C}$

\begin{tabular}{llcc}
\hline \multirow{2}{*}{ Polymer } & $\begin{array}{c}\lambda_{\max }(\mathrm{abs}) / \mathrm{nm}, \varepsilon^{\mathrm{b}} / 10^{3}, \\
\text { Stoke Shifts } / 10^{3} \mathrm{~cm}^{-1}\end{array}$ & $\begin{array}{c}\lambda_{\max }^{\mathrm{a}}(\mathrm{PL}) / \mathrm{nm}, \\
\eta / \%\end{array}$ \\
\hline P1 & Fr.1 & $462,2.0,3.91$ & $564,1.05$ \\
& Fr.2 & $563,9.5,2.10$ & $635,0.028$ \\
& Fr.3 & $586,6.2,2.53$ & $688,0.017$ \\
P2 & Fr.1 & $518(520)^{\mathrm{c}}, 9.2,3.23$ & $622(619)^{\mathrm{c}}, 0.46$ \\
& Fr.2 & $578(580)^{\mathrm{c}}, 11.9,2.62$ & $681(690)^{\mathrm{c}}, 0.043$ \\
& Fr.3 & $590(610)^{\mathrm{c}}, 7.8,2.60$ & $697(702)^{\mathrm{c}}, 0.026$ \\
P3 & Fr.1 & $506,6.8,3.42$ & $612,0.60$ \\
& Fr.2 & $566,9.6,2.45$ & $657,0.059$ \\
& Fr.3 & $580,11.9,2.89$ & $709,0.020$
\end{tabular}

${ }^{\mathrm{a}} \lambda_{\max }(\mathrm{PL})$ was recorded at $\lambda_{\max }(\mathrm{abs})$ excitation, whereas the absorbance of each fraction was $c a .0 .05$. Quantum yields $(\eta)$ were calculated in an integrating sphere with quinine sulfate as the standard. ${ }^{\mathrm{b}} \varepsilon$ was normalized by (thiophene repeating unit) ${ }^{1} \mathrm{dm}^{3} \mathrm{~cm}^{-1}$. ${ }^{c}$ Data in parentheses stand for absorption and emission maximum wavelengths of $\mathrm{P} 2$ in the solid state. The films were prepared by solvent casting technique from THF solution.

served lower emission efficiency. ${ }^{3}$

PL and absorption spectra of fraction 1 are broader than those of the second and third fractions. The Stokes shift for the first fraction is in the range of 2900-3900 $\mathrm{cm}^{-1}$, while those for the second and third fractions are in the range of $2000-2800 \mathrm{~cm}^{-1}$. This difference may be ascribed to the less rigid nature of the photoexcited state of fraction 1 compared to the other two fractions due to the unsaturated conjugation of the backbone.

The above results may provide a facile way to control the conjugation length along the polymer backbone, and thus control the emission color, by which the tedious synthesis work to tailor the structures of the main chain or side chain could be avoided. This method is specially suitable for those polymers with a lower degree of polymerization (oligomers), like the poly(3-alkoxythiophene)s, in which the emission colortuning is realizable due to the existence of the fraction with unsaturated conjugation along the main chain, and the low molecular weight fractions that are usually discarded can become useful, and thus, the cost for real application could be significantly reduced due to high content in the polymers (over $20 \%$ in our poly(3alkoxythiophene)s).

In summary, we demonstrated the synthesis of monoalkoxy substituted polythiophenes with moderately high molecular weights, which also exhibit a good solubility and film-forming ability, using the nickel(0) coupling reaction of the corresponding 3-alkoxy-2,5dibromothiophenes. Visible PL color and quantum yields are easily tuned by choosing the appropriate molecular weight sample, which is available by frac- 
tionation from its mother polymer. Besides Soxhlet extraction, other techniques, e.g., membrane or fractional GPC techniques, may be applied to achieve different molecular weight fractions to provide more detailed information in search for organic luminescent materials.

Acknowledgment. The authors thank Drs. Masao Morita, Hideaki Takayanagi, and Katsuhiko Kuroda, and Profs. Hideki Sakurai and Yasuhiro Nakadaira for their support.

\section{REFERENCES}

1. R. H. Friend, R. W. Gymer, A. B. Holmes, J. H. Burroughes, R. N. Marks, C. Taliani, D. D. C. Bradley, D. A. Dos Santos, J. L. Brédas, M. Lögdlund, and W. R. Salaneck, Nature, 397, 121 (1999); D. Fichou, Ed., "Handbook of Oligo- and Polythiophenes”, Wiley-VCH, Weinheim, Germany, 1999.

2. M. Berggren, O. Inganäs, G. Gustafsson, J. Rasmusson, M. R. Andersson, T. Hjertberg, and O. Wennerstorm, Nature, 372, 444 (1994).

3. M. R. Anderson, O. Thomas, W. Mammo, M. Svensson, M. Theander, and O. Inganäs, J. Mater. Chem., 9, 1933 (1999).

4. M. Gross, D. C. Müller, H.-G. Nothofer, U. Scherf, D. Neher, C. Bräuchle, and K. Meerholz, Nature, 405, 661 (2000); L. Groenendaal, F. Jonas, D. Freitag, H. Pielartzik, and J. R. Reynolds, Adv. Mater., 12, 481 (2000).

5. R. D. McCullough, Adv. Mater., 10, 93 (1998).

6. T. Yamamoto, Bull. Chem. Soc. Jpn., 72, 621 (1999).

7. T. Yamamoto, A. Kashiwazaki, and K. Kato, Makromol. Chem., 190, 1649 (1989).

8. G. Daoust and M. Leclerc, Macromolecules, 24, 455 (1991).

9. K. Faïd, R. Cloutier, and M. Leclerc, Macromolecules, 26, 2501 (1993).

10. S.-A. Chen and C.-C Tsai, Macromolecules, 26, 2234 (1993).

11. M. C. Gallazi, L. Castellani, R. A. Marin, and G. Zerbi, J. Polym. Sci., Part A: Polym. Chem., 31, 3339 (1993).
12. T. Yamamoto, M. Omote, Y. Miyazaki, A. Kashiwazaki, B.-L. Lee, T. Kanbara, K. Osakada, T. Inoue, and K. Kubota, Macromolecules, 30, 7158 (1997).

13. A. Iraqi, D. Clark, R. Jones, and A. Krier, Synth. Met., 102, 1220 (1999).

14. X. Hu and L. Xu, Polymer, 41, 9147 (2000).

15. B. M. W. Langeveld-Voss, R. A. J. Jassen, M. P. T. Christiaans, S. C. J. Meskers, H. P. J. M. Dekkers, and E. W. Meijer, J. Am. Chem. Soc., 118, 4908 (1996).

16. Y. Watanabe, T. Mihara, and N. Koide, Macromolecules, 30, 1857 (1997).

17. T. Yamamoto, A. Morita, Y. Miyazaki, T. Maruyama, H. Wakayama, Z.-H. Zhou, Y. Nakamura, and T. Kanbara, Macromolecules, 25, 1214 (1992).

18. T. A. Chen, X. Wu, and R. D. Rieke, J. Am. Chem. Soc., 117, 233 (1995).

19. Since mono-alkoxy thiophene is not a symmetrical molecule, there are three relative orientations available when two thiophene rings are coupled between 2- and 5- positions. The polymer may include three possible regiochemical couplings: $\mathrm{HT}$, TT, and HH. The four singlets in the aromatic region of ${ }^{1} \mathrm{H}$ NMR spectroscopy can be attributed to the four kinds of configuration triads: HT-HT, TT-HT, HT-HH, and TT-HH.

20. The introduction of the chiral side chain in P3 was aimed at investigating the $\pi-\pi$ stacking structure in the aggregates. P3 showed very weak bisignate CD (circular dichroism) signals in the solid film. This result will be published elsewhere.

21. Inganäs et al. (see ref 3 ) pointed out that the reversed addition order (slowly adding the $\mathrm{FeCl}_{3}$ slurry to the monomer dissolved in chloroform) could increase the molecular weight. We carried out the polymerization using the $\mathrm{FeCl}_{3}$ oxidation method at low temperature $\left(0^{\circ} \mathrm{C}\right)$ in both the normal and reverse addition orders, but only the insoluble products were obtained. It seems that the $\mathrm{FeCl}_{3}$ oxidation is too strong for the polymerization of the mono-alkoxy substituted thiophenes.

22. The emission efficiency in the solid state was decreased mainly due to the interchain interaction. Adopting bulky side chains could be an answer for solving this problem. ${ }^{3}$ 